During its first year, ARET determined to lay down a baseline of information from which to measure the results of the special management in years to come. Accordingly, surveys were carried out of the soils, hedgerows, woodlands, wetlands, flora, gamebirds, songbirds, mammals, and insects. At the same time, plans were drawn up for the new management regimes. Most have already been put in hand; the others will start soon. Among the special features of the farming are:

Set-aside Areas:- A mixture of rotational and nonrotational set-aside areas is used. The Game Conservancy Trust recommends this option as the best for game and wildlife conservation. A network of strips and blocks of non-rotatational set-aside areas is established along field margins and across large fields. Three blocks (whole or half fields) of rotational set-asides make up the statutory area requirement.

Hedgerows:- An extensive programme of hedgerow restoration and management has been instituted. In the UK, government grants are available to subsidize the costs, but good hedgerows are in any case wise agricultural practice, sheltering fields and reducing soil erosion.

Conservation Headlands:- Conservation headlands are being used around most cereal fields. Six-metres-wide strips are selectively sprayed, to control only the most damaging weeds; the less harmful species remain as hosts for butterflies and other insects which form the diet of songbird and gamebird chicks.

Beetle Banks:- These have been created across the middle of large fields, to provide overwintering habitat for aphid predators - thus protecting the crop and reducing the need for insecticides. One special feature is the gap at each end, which allows modern farm machinery to work the field without disruption.

Woodlands:- Neglected woodlands are being thinned and new woods have been planted with long edges of shrubby cover to help wild gamebirds.

Wetlands:- The farm has two large ponds, both of which were overgrown, silted up, and polluted. The restoration programme began by felling trees to let light in, dredging the ponds, and stopping the pollution at source. In time it is hoped that there will be a sustainable trout fishery which will help to pay for this work.

Gamekeeping:- ARET's gamekeeper undertakes habitat management and the control of common predators to preserve game and other wildlife. The game shooting will bring in important income to pay for some of the conservation work.

\section{Monitoring of Results and Conclusion}

The effects of these management projects on the fauna and flora of the ARET farm are being monitored, recorded, and published. All the conservation management is fully assessed in terms of materials and labour costs. This attention to the financial picture will eventually show us the extent to which farmers can manage their land sustainably with conservation in mind, whilst still making a realistic living.

Although the ARET project is still in its infancy, the early results are highly encouraging. In the first growingseason since the 'new farming' began, yields and profit have been consistent with the average for farms of this size. No serious agricultural problems have arisen from the conservation measures implemented. Gamebirds and songbirds have bred much more successfully than latterly, and the number of Hares (Lepus europaeus) has increased. Equally important, large numbers of visiting farmers, journalists, politicians, and officials, have seen a really practical demonstration of the way farming and Nature conservation can go hand-in-hand. In 1994 ARET added the Duke of Edinburgh, with a representative of his own estate staff, to its list of interested visitors wishing to see this special farming in action.

CHARLES NODDER
The Game Conservancy Trust
Fordingbridge
Hampshire SP6 IEF
England, UK.

Charles Nodder

Fordingbridge

England, UK.

\title{
Biodiversity Leadership Awards
}

\section{ANNOUNCEMENT}

$\mathrm{T}_{\mathrm{T}}^{\mathrm{h}}$ The Bay Foundation and the Josephine Bay Paul \& C. Michael Paul Foundation announce a collaborative programme for three Biodiversity Leadership Awards of . US $\$ 180,000$ each to individuals whose work demonstrates leadership in science or policy related to the global loss of biological diversity. Ten distinguished educational and research institutions having active programmes in conservation science, policy, or environmental studies, will conduct a world-wide search for candidates. Each of these institutions has appointed an advisory panel representative to help set the programme guidelines, to submit three nominations from the institution, and to serve on the selection panel to recommend to the Foundation the finalists for each category.

The Foundations have targeted three broadly-defined categories - conservation biology, environmental studies, and conservation science advocacy - where they believe such grants could inspire efforts and bring attention to the related issues of biological extinction, habitat preservation, and 'sustainable development'.

For Conservation Biology:- To an individual whose work in conservation biology is distinguished by its pioneering nature, creative excellence, and potential for mitigating the species extinction crisis.

For Environmental Studies:- To an individual whose work in environmental science or related studies is making a significant contribution to the understanding and stewardship to the Earth's resources.

For Conservation Science Advocacy:- - To an individual whose work in education, policy, or advocacy, brings scientific conclusions to bear on the problems of 'sustainable development' and the conservation of biological diversity.

The ten participating institutions are The American Museum of Natural History, The Wildlife Conservation Society, The Missouri Botanical Garden, The Natural History Museum of Los Angeles County, The Zoological Society of San Diego, the Marine Biological Laboratory, the Salk Institute for Biological Studies, The Santa Fe Institute, and Harvard and Yale Universities. Each institution will submit three nominations. Only one of an institution's nominations can be of a person employed by, or principally situated at, the nominating institution, and one of the persons nominated must be working in a developing country. Nominations will only be accepted from the participating institutions. 


\section{GuIDELINES}

The Foundations have encouraged the participating institutions to seek the nominations of diverse candidates in their early or mid-careers who have demonstrated excellence in solving problems relevant to conserving biodiversity.At least one of the three awards will be to an individual working in a developing country. While the awards will fittingly recognize and reward leadership accomplishments, the essential goal of the programme is to find outstanding individuals whose work will be meaningfully advanced by the award.

The Foundations expect that nominees will represent an array of disciplines in the basic and applied sciences and other areas of study. These may include (but are not limited to) economics, history, computational biology, ethics, forestry, agronomy, veterinary medicine, public policy, and other traditional, combined, or emerging, fields which may prove germane to efforts to prevent biodiversity loss. It is the policy of the Foundations to make awards without regard to gender, race, ethnicity, age, citizenship, sexual orientation, or handicapping conditions.

Nominations, each with a supporting statement from the nominating institution, had to be received by the Foundations by May 1. By August 1 the Foundations will circulate to the panel members the assembled sets of nominee portfolios, including the nominees' resumés, brief statements of their three most significant publications or other accomplishments, and statements, of not more than two pages, explaining how their work would be advanced if they should receive the award.

On 29 September 1995 the panellists will meet in New York City to present and review all of the nominee portfolios, grading each for the final review of the top nine to twelve candidates. The following day, without disclosure of the order of ranking of the top candidates on the first day, the panellists will select the award finalist for each category. On the second day of panel proceedings, no panellist will be able to vote for the three nominees of his or her institution. Nominations will be received only from the participating institutions, and panel proceedings will be confidential.

The recipients will be announced bythe Foundations not later than 15 November 1995 . The awards will be payable in equal instalments over a period of three years beginning in 1996, or in such other manner as may be individually arranged with the agreement of the recipients. The Foundations have not announced any plans for a second round or possible further rounds* of awards, but are exploring the possibility of obtaining additional sponsors to expand the programme.

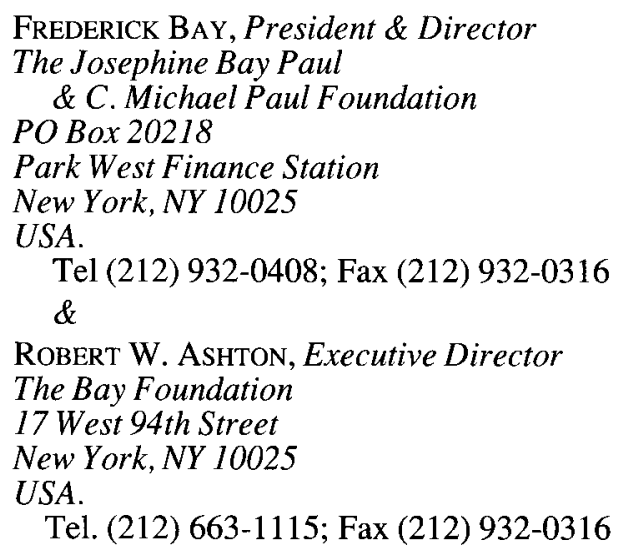

* In case no representative of either of the sponsoring Foundations corrects a proof of this account, we have to admit that the four words of text immediately preceding this asterisk were inserted by us without permission. The entire prospect of continuation of such good news in these times of desperate shortage of any funds for environmental/conservational work as this chance seemed to suggest was just too good to miss. - Ed.

PS. Proof was corrected by first-named Author without comment on this point, so we live in hope. - Ed.

\section{WEC Honours Ciba-Geigy Limited at Eleventh Annual WEC Gold-medal Dinner}

$\mathrm{C}$ liba-Geigy Limited has received the WEC 1995 Gold Medal for International Corporate Environmental Achievement from the World Environment Center (WEC). This tribute is presented annually to recognize a corporation with substantial international operations that has an outstanding and well-implemented world-wide environmental policy.

Dr Alex Krauer, Chairman of the Board and Chief Executive Officer (CEO) accepted the 1995 WEC Gold Medal on behalf of Ciba's 83,000 employees around the world. The award was presented by Gautam S. Kaji, Managing Director of the World Bank, at a dinner held in the National Building Museum in Washington, DC. The event was attended by over 500 leaders of industry, government, nongovernmental organizations, the diplomatic corps, the academic and scientific communities, and the media.

'We are pleased to honour Ciba-Geigy Limited for its corporate policy which requires an equal balance between long-term economic success, social responsibility, and responsibility for the environment', said Antony G. Marcil, President and CEO of WEC. 'Their efforts are borne out by the high level of personal environmental leadership that has typified Ciba's Chief Executive Officers, and the clear understanding that the successful implementation of Ciba's policies and principles is the obligation of all employees world-wide.'

Ciba-Geigy is a leading world-wide biological and chemical group, dedicated to satisfying needs in healthcare, agriculture, and industry, with innovative, valueadding, products and services. Under the topic of environmental responsibility, Ciba's corporate policy states that, '... respect for the environment must be part of everything we do. We design products and processes to fulfill their purpose safely and with as little environmental impact as possible. We use natural resources and energy in the best possible way, and reduce waste in all forms. It is our duty to dispose of all unavoidable waste by using state-of-the-art technology.'

Previous recipients of the WEC Gold Medal have been: S.C. Johnson and Son, Inc.; Xerox Corporation; The Procter \& Gamble Company; Rohm and Haas Company; IBM Corporation; The Dow Chemical Company; The British Petroleum plc; E.I. du Pont de Nemours \& Co.; Exxon Corporation; and 3M.

WEC, an independent, not-for-profit, non-advocacy organization, contributes to environmentally sustainable development world-wide by strengthening industrial and urban environment, health, and safety policy and practices. 